\title{
Investigation of the atmospheric water budget of the BALTEX area using NCEP/NCAR reanalysis data
}

\author{
By EBERHARD RUPRECHT* and TORBEN KAHL ${ }^{\dagger}$, Institut für Meereskunde an der Universität Kiel, \\ Düsternbrooker Weg 20, D - 24105 Kiel, Germany
}

(Manuscript reveived 2 January 2003; in final form 21 May 2003)

\begin{abstract}
The Baltic Sea Experiment BALTEX is the European regional project of GEWEX. The aim of BALTEX is to improve the knowledge of the water and energy cycle of the Baltic Sea including its catchment area (the BALTEX area). In this study the NCEP/NCAR reanalysis data (Kalnay et al. Bull. Am. Meteorol. Soc., 1996, 77, 437-471) are used to derive the mean atmospheric water budget over the BALTEX area. For this purpose the horizontal water vapour fluxes are calculated. In the long-term mean (here $1948-$ 2000) the vertically integrated divergence of these fluxes must balance evaporation minus precipitation. The latter two are provided by the NCEP/NCAR reanalyses. The water budget over the BALTEX area is, however, not closed. An error estimation is performed. The divergence of the water vapour flux is corrected due to the mass balance correction technique (Alestalo, Tellus, 1981, 33, 360-371). Large differences are obtained between the precipitation given by the NCEP/NCAR reanalysis and by the analysis of the observations by Rubel and Hantel (Meteorol. Atmos. Phys., 2001, 77, 155-166). With these analysed precipitation data and the corrected divergence of the water vapour fluxes the imbalance of the water vapour budget could be remarkably reduced.
\end{abstract}

\section{Introduction}

The main argument for implementing the Global Energy and Water Cycle Experiment (GEWEX) of the World Climate Research Programme was the statement that the present knowledge of the freshwater and energy budgets on a regional or even global scale is far from adequate (WMO, 1990). The principal cause of this ignorance is a lack of reasonable data to analyse the necessary fields, e.g. distribution of humidity. The spatial and temporal variability of humidity can be very large, thus representative observations are rare. The main experiments of GEWEX aim to understand the global-scale water budget, and regional projects have been implemented to study regional-scale budgets. The Baltic Sea Experiment BALTEX (Raschke

\footnotetext{
*Corresponding author: e-mail: eruprecht@ifm.uni-kiel.de

†Present affiliation: Max-Planck-Institut für Meteorologie, Bundesstrasse 55, D - 20146 Hamburg.
}

et al., 2001; BALTEX, 1995) is the European regional experiment in the framework of GEWEX. Improvement of the knowledge of the water and energy cycles in the Baltic Sea catchment area is the goal of this programme. Although observations in this region are relatively dense, even here more data are needed, to investigate the water cycle in detail. BRIDGE (BALTEX, 1997) was implemented as a BALTEX Main Experiment with the goal, to obtain better and more comprehensive observations. All available data should be used to analyse the regional budget. In particular, an analysis of long-period data is needed as a reference for the short-term observations during BRIDGE.

The aim of this study is to derive the regional-scale atmospheric water budget of the Baltic Sea and its catchment area (the BALTEX area) on the basis of the operational data of the NCEP/NCAR reanalysis (Kalnay et al., 1996). Operational analysis has improved significantly during the last 20 years, particularly with the outcome of the reanalysis projects. Mo 
and Higgins (1996) stated that the hydrologic cycle revealed by operational analysis before 1980 was unrealistic. And Rasmusson and Mo (1996) concluded that prior to 1980 , operational forecast and analysis products provide a poor picture of the atmospheric branch of the global hydrological cycle. Rasmusson and Mo used a two-year analysis and found that for regional water budgets, here over the United States, major analysis problems arose which were mainly related to large-scale terrain features e.g. Rocky Mountains. Mo and Higgins applied 9-year (March 1985November 1993) NCEP reanalysis data and compared the budget results with those derived from the NASA analysis. Large differences arose in the two regional budgets. Thus, Mo and Higgins (1996) point to the 40year NCEP/NCAR reanalysis data which they classified to be likely a very important source of information on the general feature of the hydrologic cycle.

Trenberth and Guillemot (1998) have used the NCEP/NCAR reanalysis data to derive the global hydrological budget. Their results show that the budget is not in balance over many mountain regions. Despite of this fact we think that it is worthwhile to investigate the atmosphere water budget over the BALTEX area with these reanalysis data, because data density and quality are high compared to earlier studies of this region (Simojoki, 1948; Brogmus, 1952; Palmen, 1963; Speth and Skade, 1977; Alestalo, 1983).

To our knowledge there does not exist any recent study of the atmospheric hydrological budget of the BALTEX area based on observational data. Heise (1996) and Karstens et al. (1996) have evaluated simulations with their regional models. With the European model of the German Weather Service, Heise (1996) closed the hydrological budget with the convergence of the horizontal water vapour flux as residuum. Karstens et al. (1996) calculated all components from the results of their regional model REMO and discussed daily results of one month (June 1993). In the frame of BALTEX a number of studies were carried out to calculate the hydrological budget at the surface of the Baltic Sea (Omstedt et al., 1997; Omstedt and Rutgersson, 2000; Omstedt et al., 2000; Lindau, 2002). They show that in the long-term mean precipitation exceeds evaporation of Baltic Sea. The focus of this study is, however, to determine the divergence of the vertically integrated horizontal water vapour fluxes over the BALTEX area and compare it with the difference between evaporation and precipitation. The long-term mean of the two budget components should balance, assuming storage is negligible.

\section{Data and methods}

To study the atmospheric water budget of the BALTEX area, the vertically integrated water budget components have been computed and analysed together with the budget equation. In these components we consider only water in the gas phase because the terms of the other two phases are negligible small compared to those of the water vapour. The total water vapour content $W$ is determined by the vertically integrated specific humidity $q$ :

$W=\int_{p_{\mathrm{u}}}^{p_{\mathrm{s}}} q \frac{\mathrm{d} p}{g}$

where $p$ is atmospheric pressure, the index s/u denotes surface/upper level, and $g$ is the gravitational force. The vertically integrated instanteneous water vapour flux $Q$ is given by

$Q=\int_{p_{\mathrm{u}}}^{p_{\mathrm{s}}} q \boldsymbol{v}_{h} \frac{\mathrm{d} p}{g}$

with $\boldsymbol{v}_{\mathrm{h}}$ the horizontal wind velocity.

The temporal mean of the total flux $\bar{Q}$ is conventionally divided into its mean and eddy part:

$\bar{Q}=\int_{p_{\mathrm{u}}}^{p_{\mathrm{s}}} \overline{q \boldsymbol{v}_{h}} \frac{\mathrm{d} p}{g}=\int_{p_{\mathrm{u}}}^{p_{\mathrm{s}}} \bar{q} \overline{\boldsymbol{v}}_{\mathrm{h}} \frac{\mathrm{d} p}{g}+\int_{p_{\mathrm{u}}}^{p_{\mathrm{s}}} \overline{q^{\prime} \boldsymbol{v}_{\mathrm{h}}^{\prime}} \frac{\mathrm{d} p}{g}$.
total flux
mean flux eddy flux

The overbar denotes the time average (here over $53 \mathrm{yr}$ ) and the prime the anomaly (here 6-hourly values). Since the reanalysis data are only available at certain pressure levels and values at $1000 \mathrm{hPa}$ are always given (partly as extrapolation), the vertical integration is carried out between fixed levels $\left(P_{\mathrm{s}}=1000 \mathrm{hPa}\right.$ and $\left.P_{\mathrm{u}}=300 \mathrm{hPa}\right)$.

The water vapour balance equation is applied in the vertically integrated form:

$\frac{\partial W}{\partial t}+\nabla \cdot \mathbf{Q}=E-P$.

$E$ is evaporation and $P$ precipitaion.

The water vapour storage term $\partial W / \partial t$ becomes very small and can be neglected if the averaging period is several years. Thus, the divergence of $\bar{Q}$ is in balance with the difference of evaporation $\bar{E}$ and precipitation $\bar{P}$. To derive the water vapour budget for a larger 
region eq. (4) has to be spatially averaged (Smirnov and Moore, 1999).

$\left\langle\frac{\partial W}{\partial t}\right\rangle+\frac{1}{A} \oint \mathbf{Q} \cdot \boldsymbol{n} \mathrm{d} \gamma=\langle E-P\rangle$.

$A$ denotes the area of the region, \langle\rangle the spatial mean and $\boldsymbol{n}$ the outward unit vector normal to the lateral boundary element $\gamma$ of the area $A$.

The NCEP/NCAR reanalysis data for the time period 1948-2000 (Kalnay et al., 1996) are used to calculate the budget terms. The 6-hourly wind components $u, v$ and specific humidity $q$ are given at a $2.5^{\circ} \times 2.5^{\circ}$ grid and eight vertical levels; precipitation and evaporation are available as monthly means at a Gaussian grid (about $1.875^{\circ}$ lat $\times 1.9^{\circ}$ long).

The output variables of the reanalysis are classified into four categories, depending on the influence of the model. The wind components are type A variables (strongly influenced by the observed data); specific humidity $q$ is a type B variable (observational data affect $q$ but there is a strong influence of the model), precipitation and evaporation as type $\mathrm{C}$ variables are solely derived from the model fields, no direct observations are included (Kalnay et al., 1996). Seasons are defined according to the general convention [spring: March, April, May (MAM); summer: June, July, August (JJA); fall: September, October, November (SON); winter: December, January, February (DJF), whereby the given year corresponds to the January of the winter season].

\section{Water vapour content}

The total amount of water vapour over the BALTEX area is the first quantity to be discussed. Figure 1 shows that the 53-yr mean of $W$ is almost zonally distributed with $16 \mathrm{~kg} \mathrm{~m}^{-2}$ in the south decreasing to $10 \mathrm{~kg} \mathrm{~m}^{-2}$ in the north-west area. The spatial average over the BALTEX area is $13.7 \mathrm{~kg} \mathrm{~m}^{-2}$. There exists a slight excess of $W$ over the Baltic Sea compared to the adjacent land areas. The seasonal variability of $W$ is large. In winter, the mean value for the BALTEX area is $7.6 \mathrm{~kg} \mathrm{~m}^{-2}$, i.e. only about one third of the mean summer value $\left(21.1 \mathrm{~kg} \mathrm{~m}^{-2}\right)$. The summer-winter difference increases from west $\left(10-12 \mathrm{~kg} \mathrm{~m}^{-2}\right)$ to east (14$16 \mathrm{~kg} \mathrm{~m}^{-2}$ ). The large differences in the east are caused by the large summer values due to the continentality. The interannual variability of the total water vapour

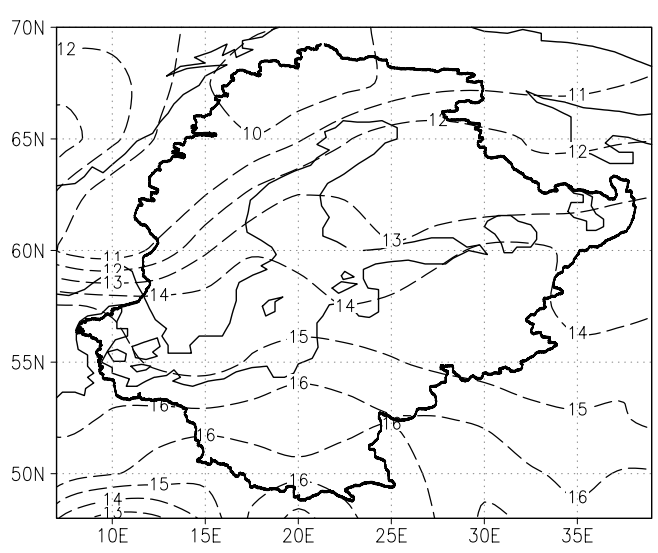

Fig. 1. Annual mean of the water vapour content $\left(\mathrm{kg} \mathrm{m}^{-2}\right)$ over the BALTEX area. Data: NCEP/NCAR Reanalysis 1948-2000 (full thick line = boundary of the BALTEX area).

content over the BALTEX area is quite large (Fig. 2). A decreasing trend is observed in these time series. In particular, the annual means before 1960 show high values. The trend is mainly the result of the large annual means of the years before 1960. Thus, we assume that Fig. 2 shows a spurious trend produced by the change of the radiosonde network at the end of the 1950s (Kistler et al., 2001). All three curves in Fig. 2 show large interannual variability. However, only the summer values are high correlated with the annual values $(0.81)$, whereas the correlation between winter and annual mean is not significant $(0.27)$. The same is true for the correlation between the winter and summer time series of $W$. However, the water vapour content of the summer is significantly correlated with the water vapour content of the following winter $\left(r_{s, w+1}=\right.$ 0.51 ). Thus, the winter $W$ seems to be influenced by the water vapour content of the previous summer. Whether this relation is a local effect (the high soil moisture of the Baltic Sea catchment area as a consequence of a moist summer, less ice cover of the Baltic Sea following a warm, moist summer) or whether it is produced by variations in the general circulation is not yet known. The water vapour content over the BALTEX area during winter is closely related to the North Atlantic Oscillation (NAO), the dominant atmospheric circulation mode over the North Atlantic. The NAO is characterized by the NAO index [=difference of the normalized sea level pressure at Lisbon (Portugal) and Stykkisholm (Iceland)]. The NAO explains 


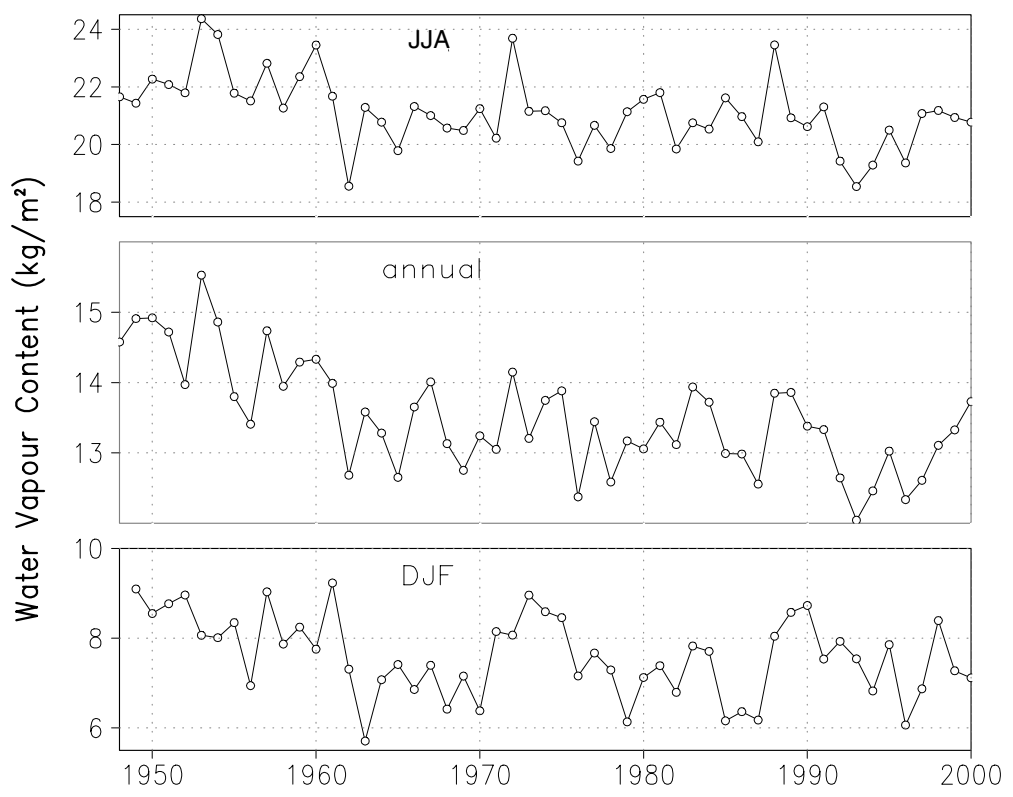

Fig. 2. Time series of the mean water vapour content over the BALTEX area $\left(\mathrm{kg} \mathrm{m}^{-2}\right)$ for summer (JJA) (top), winter (DJF) (bottom) and annual mean (middle).

about $17 \%$ of the variability of the winter water vapour content over the BALTEX area. In high NAO winters the westerlies are stronger and they transport warm and moist airmasses from the Atlantic into the BALTEX area. Winters with a low NAO index are colder and drier than in the mean (Hurrell, 1995; Ruprecht et al., 2002).

\section{Water vapour flux}

Atmospheric water budget studies aim to answer the question whether the water vapour, which yields the precipitation of a certain area, is provided by an external source, flux into the area through the lateral boundaries, or by the internal source, evaporation. Two different methods have been used to determine the divergence of the water vapour flux: first, determination of the fluxes through the lateral boundaries of the BALTEX area [eq. (5)], and second, calculation of the fluxes and their divergence at each grid point. The first method yields the possibility to separately examine inflow into and outflow out of the area. A similar method was used by Cadet and Nnoli (1987) for Africa and by Rasmusson (1967) for North America who showed that this method works best if the divergence for large areas is to be determined.

\subsection{Flux through the lateral boundaries}

The mean transport through the BALTEX boundaries is displayed in Fig. 3. The strongest inflow into the BALTEX area takes place in the southwest of the region, and large outflow exists through the eastern boundary. Small fluxes have been obtained at the northern and southern boundaries with a small outflow in the north and slight inflow in the south. Integration about the lateral boundaries of the BALTEX area yields a positive annual net transport into the BALTEX area. The mean annual net water vapour flux amounts to $14.4 \times 10^{6} \mathrm{~kg} \mathrm{~s}^{-1}$, corresponding to a gain of water of $215 \mathrm{~mm} \mathrm{yr}^{-1}$.

In the 1950s inflow and outflow were almost balanced (Fig. 4). This period was followed by years with a large positive net transport. Strong convergence of the water vapour flux also exists at the end of the 1980s and the beginning of the 1990s. Reasons for changes in the net transport are under investigation. For the annual mean, there exists a high correlation between inflow and outflow $(r=0.95)$, but neither of the two components is significantly correlated with the net flow. During winter season, the inflow is, however, well correlated with the net flow $(r=0.85)$. Both are related to the North Atlantic Oscillation; the correlation coefficients with 


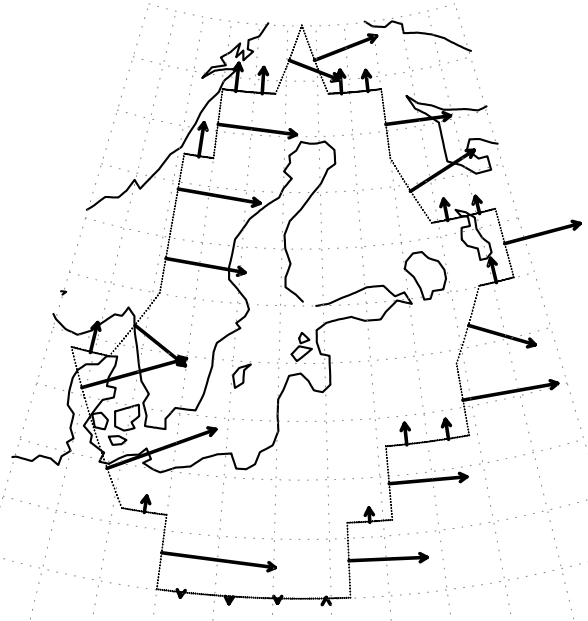

$100(\mathrm{~kg} / \mathrm{ms})$

Fig. 3. Vertically integrated water vapour flux $\left(\mathrm{kg} \mathrm{m}^{-1} \mathrm{~s}^{-1}\right)$ through the lateral boundaries (approximated) of the BALTEX area (vector scale is given by the arrow below the figure). the NAO index are 0.77 (inflow) and 0.59 (net flow). This means that during high NAO winters the BALTEX area experiences a strong inflow and a large net gain of water vapour, as for example observed at the end of the 1980s and the beginning of the 1990s. These results for the BALTEX area are in agreement with the findings of Hurrell (1995) and Ruprecht et al. (2002), who showed that during high (low) NAO winters water vapour transport is mainly towards Northern (Southern) Europe. In contrast to the winter season, the influence from outside is weak during the summer. Local processes are mainly responsible for the divergence of water vapour flux.

\subsection{Spatial distribution of the flux divergence}

The spatial distribution of the divergence has been derived from the calculated fluxes at each grid point. Figure 5 shows a marked convergence maximum in the northwest of the BALTEX area. This maximum extends along the Scandinavian Mountains to the south. The easterly mean flux and northerly eddy flux contribute both to this maximum (Figs. 6 and 7) due to
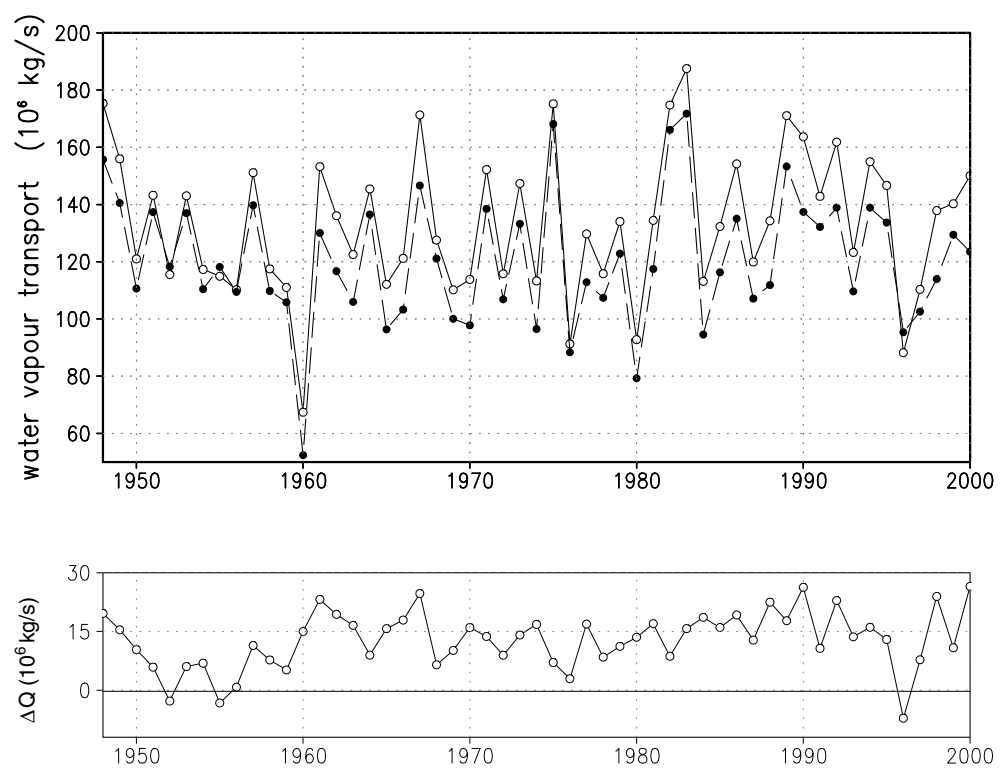

Fig. 4. Time series of the vertically integrated water vapour flux $Q$ into (full line) and out (dashed line) of the BALTEX area in $10^{6} \mathrm{~kg} \mathrm{~s}^{-1}$ (top); the difference between in- and outflow $(\Delta Q)$ is given at the bottom. 


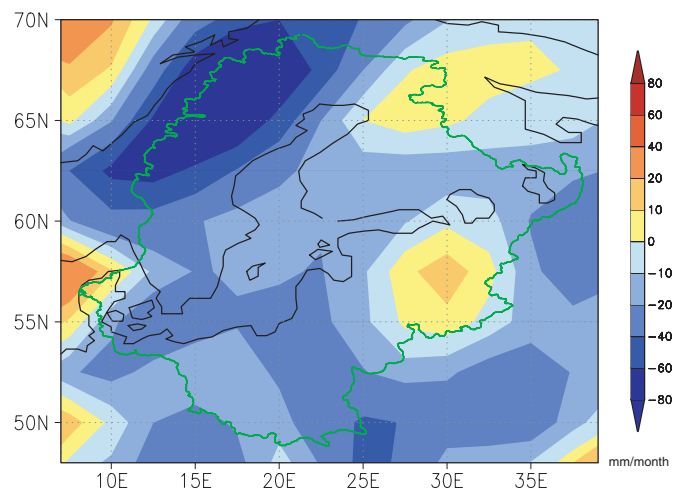

Fig. 5. Divergence of the vertically integrated water vapour flux averaged over the period 1948-2000 (mm month ${ }^{-1}$ ) (green line $=$ boundary of the BALTEX area).

its direction relative to the Scandinavian mountains. Small regions with divergent fluxes are found south of the Lake Ladoga and northeast of Finland. In the other parts of the BALTEX area, the water vapour flux is convergent with values between -10 and $-40 \mathrm{~mm}$ month $^{-1}$. The division of the total water vapour flux in its mean and eddy part is shown in Fig. 6. The results agree in general with those of other studies that the mean flux is about five times larger than the eddy flux (Rasmusson and Mo, 1996). The maximum of the mean flux of $70 \mathrm{~kg} \mathrm{~m}^{-1} \mathrm{~s}^{-1}$ is located over the northern part of Germany, the minimum of less than

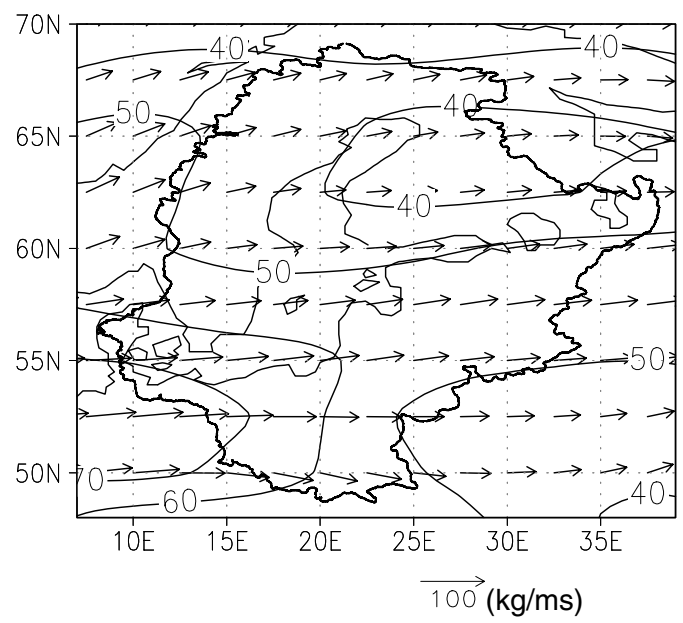

$40 \mathrm{~kg} \mathrm{~m}^{-1} \mathrm{~s}^{-1}$ is found over Finland. The two fluxes are almost perpendicular to each other, the mean flux is nearly zonally aligned, nearly parallel to the isolines of the total water vapour content. In contrast the eddy fluxes are mainly meridional.

Although the mean flux is much larger than the eddy flux, the resulting divergences are of the same size (Fig. 7). This fact confirms the results of the previous section (Fig. 3) that most of the water vapour is transported through the BALTEX area and only a small part (10-20\%) is included in the regional budget. The mean flux has its maximum convergence in the northwest of the region mainly caused by the zonality of the flux. As we shall discuss below, part of this maximum is probably caused by erroneous data over the mountains, a well known problem in this (Trenberth and Guillemot, 1998) and in other operational data sets (Mo and Higgins, 1996; Rasmusson and Mo, 1996). The mean flux is also convergent over the Baltic Sea, but in the east, from Finland to Belarus, it is slightly divergent. The more meridionally directed eddy flux is partly blocked at the southern and eastern side of the mountains, where it attains its maximum convergence of $-60 \mathrm{~mm} \mathrm{month}^{-1}$. Over the other parts of the BALTEX area the flux divergence is more irregular.

\subsection{Error estimation of the flux divergence}

In the last section it was mentioned that the distribution of the flux divergence over the Scandinavian

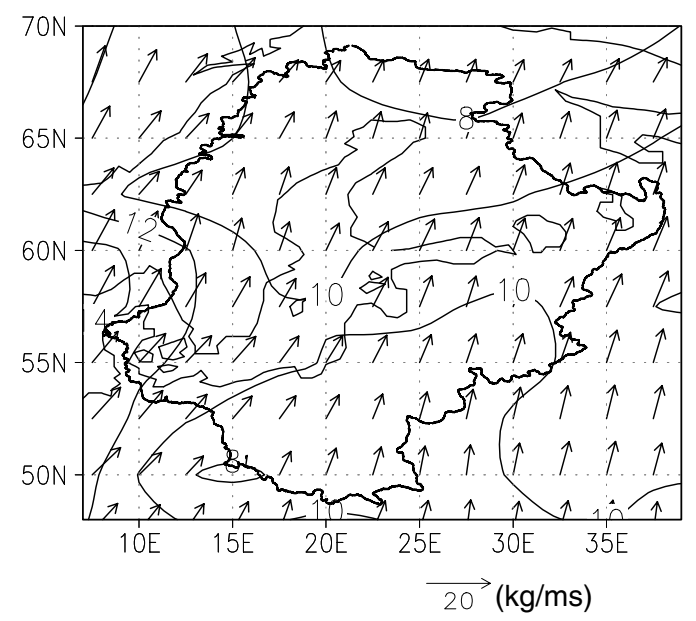

Fig. 6. Mean (left) and eddy (right) water vapour flux $\left(\mathrm{kg} \mathrm{m}^{-1} \mathrm{~s}^{-1}\right)$ averaged over the period 1948-2000; vector scale is given below each figure, contour lines give flux magnitudes (contour interval is $10 \mathrm{~kg} \mathrm{~m}^{-1} \mathrm{~s}^{-1}$ for the mean and $2 \mathrm{~kg} \mathrm{~m}^{-1} \mathrm{~s}^{-1}$ for the eddy flux).

Tellus 55A (2003), 5 

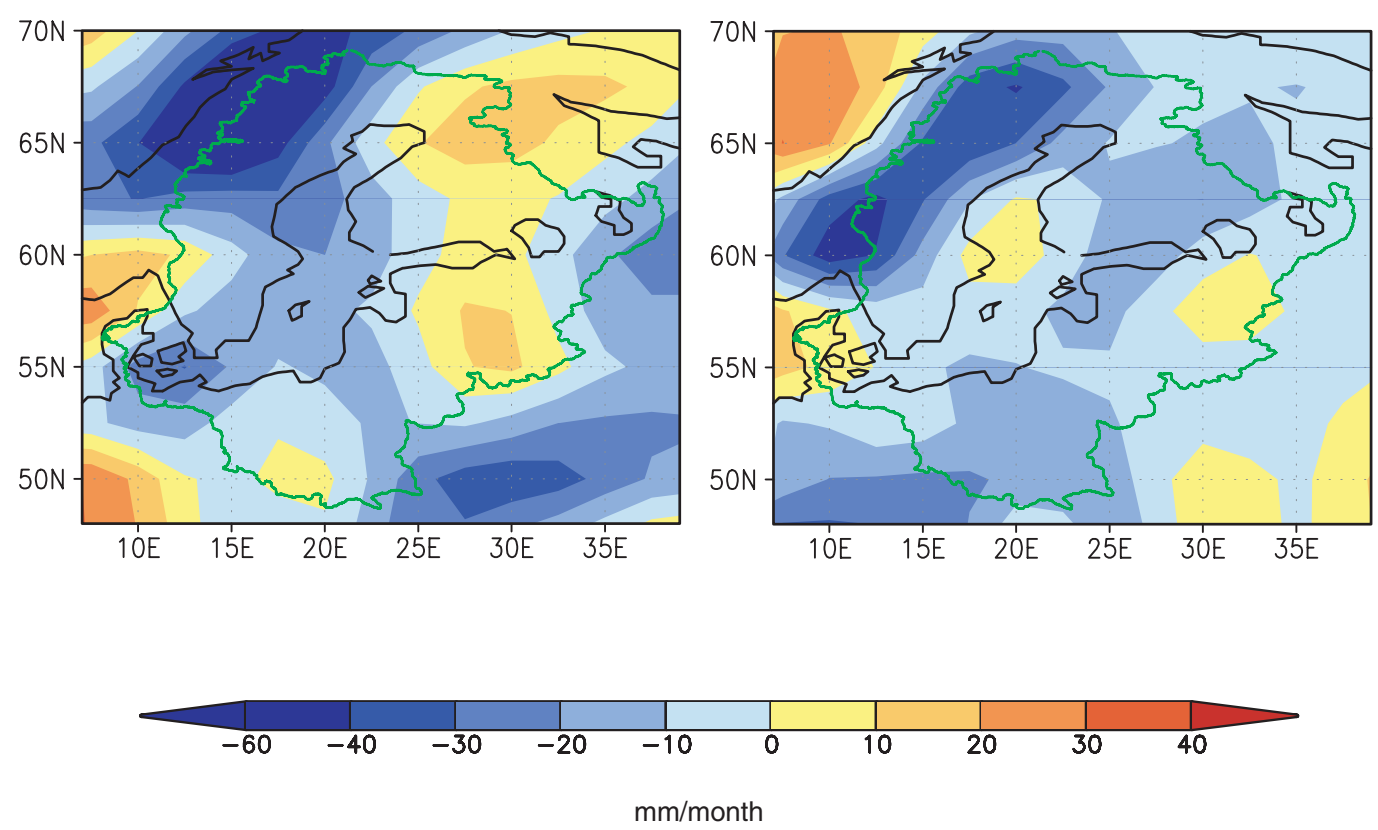

Fig. 7. Divergence of the vertically integrated mean (left) and eddy (right) water vapour flux averaged over the period 1948-2000 (mm month $\left.{ }^{-1}\right)$.

mountains may be erroneous. Therefore, an error estimation is performed. A large contribution to the erroneous divergence of the water vapour flux comes from the imbalance of the mass budget due to inaccurate wind observations; Alestalo (1981) has introduced a mass balance correction for the different atmospheric fluxes. Based on these ideas we calculated the divergence of the vertically integrated horizontal mass flux $\mathbf{M}_{\mathbf{h}}$ over the BALTEX area:

$\boldsymbol{\nabla} \cdot \mathbf{M}_{\mathbf{h}}=\nabla \cdot \int_{p_{\mathrm{u}}}^{p_{\mathrm{s}}} \frac{1}{g} \mathbf{v}_{\mathbf{h}} \mathrm{d} p$.

The time mean of $\boldsymbol{\nabla} \cdot \mathbf{M}_{\mathbf{h}}$ must be zero at each gridpoint, assuming that the variation of surface pressure is small and that there is no exchange with the stratosphere. The long-term mean vertically integrated mass flux divergence derived from the NCEP/NCAR reanalysis data, however, shows quite large convergence and divergence maxima in particularly over the mountains (not shown). The calculation yields a mean convergence of the mass flux of $-3.84 \times 10^{-4} \mathrm{~kg}$ $\mathrm{m}^{-2} \mathrm{~s}^{-1}$ over the BALTEX area. This would give an increase of the mean surface pressure of $0.8 \mathrm{hPa}$ per $6 \mathrm{~h}$.

These results clearly confirm the findings of earlier studies (e.g. Trenberth and Guillemot, 1998) that the
NCEP/NCAR reanalysis data yield unrealistic divergence values particularly in regions with high mountains. In this data set values at the $1000 \mathrm{hPa}$ level are always included even in mountain regions. Where this level is situated beneath the surface, extrapolation provides the values down to the $1000 \mathrm{hPa}$ level.

The error in the divergence of the water vapour flux (caused by the imbalance of the mass flux) is determined by:

$E(\boldsymbol{\nabla} \cdot \mathbf{Q})=\hat{q} \boldsymbol{\nabla} \cdot \mathbf{M}_{\mathbf{h}}$.

$\hat{q}$ is the vertically averged time mean of the specific humidity $q . E(\boldsymbol{\nabla} \cdot \mathbf{Q})$ is subtracted from $\boldsymbol{\nabla} \cdot \mathbf{Q}$ to correct for the mass flux imbalance. The distribution of this correction term is shown in Fig. 8. Over large parts of the BALTEX area the corrections amount to values between ${ }^{-} 5$ and $5 \mathrm{~mm}$ month $^{-1}$. However, large negative values $\left(>-10 \mathrm{~mm} \mathrm{month}^{-1}\right)$ are calculated in the northwest of the area and weaker ones at the southern coast of the Baltic Sea. Positive values $(>10 \mathrm{~mm}$ month $^{-1}$ ) occur in the east of the area, and in particularly over southern Norway as an effect the Norwegian Mountains. On average, the mean error for the BALTEX area is $-1.4 \mathrm{~mm} \mathrm{month}^{-1}\left(=-16 \mathrm{~mm} \mathrm{yr}^{-1}\right)$, i.e. the long-term annual mean of the water vapour flux, 


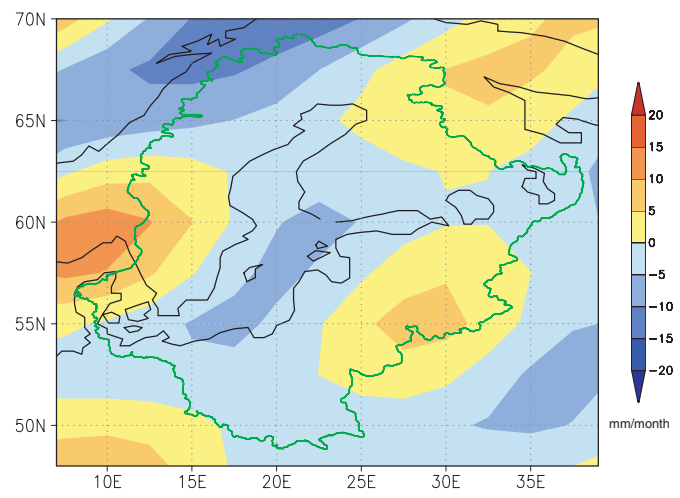

Fig. 8. Correction term for the water vapour flux divergence $\left(\mathrm{mm}\right.$ month $^{-1}$ ) caused by the imbalance of the mass flux [see equ. (7)].

calculated from the NCEP/NCAR reanalysis data, is $16 \mathrm{~mm} \mathrm{yr}^{-1}$ too convergent over the BALTEX area. This is an error of $7.7 \%$.

The attempt to reduce this error by replacing the $1000 \mathrm{hPa}$ data by the surface data (which are given in the NCEP/NCAR reanalysis) at each grid point was not successful. The error became even larger. Thus, we must conclude that the reanalysis data are not able to resolve orographic differences well enough.

\section{Evaporation and precipitation}

Evaporation $E$ and precipitation $P$ represent the surface branch of the atmospheric water budget. Although at least precipitation is operationally observed ( $E$ is determined only at very few locations of the globe) these observations are not yet operationally included in the assimilation process of forecast models. That means $P$ and $E$ are output variables of the forecast model and they are not influenced by direct observations. It is well known today that the forecast of precipitation (and evaporation) provides the largest problems in weather prediciton. This is also true for the NCEP/NCAR reanalysis data. Kistler et al. (2001) warned that those data in the NCEP/NCAR reanalysis like precipitation and surface fluxes should be used with caution. Mo and Higgins (1996) determined a 9-yr mean of $E-P$ over the continental United States of America, the NCEP/NCAR reanalysis data yield positive values over large areas so that a negative runoff was obtained over this continental area.

The 53-yr mean of $E-P$ over the BALTEX area is given in Fig. 9. It shows that precipitation exceeds

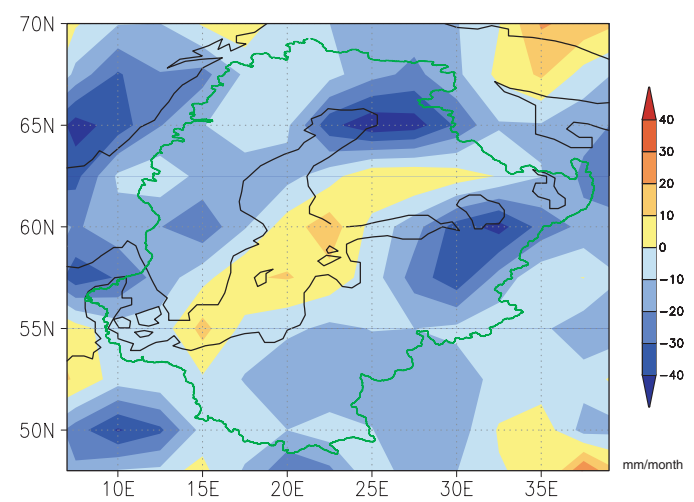

Fig. 9. Evaporation minus precipitation $\left(\mathrm{mm} \mathrm{month}{ }^{-1}\right)$ averaged over the period 1948-2000.

evaporation in most parts of the BALTEX area. This is particularly true over northern Finland and south of Lake Ladoga. Here precipitation exceeds evaporation by about $40 \mathrm{~mm}$ month $^{-1}$. These maxima coincide with the maxima of precipitation in the same areas (not shown). Only over the Baltic Sea and southern Finland is evaporation slightly higher than precipitation. Averaged over the whole BALTEX area, $E-P$ is negative with a precipitation excess of $12 \mathrm{~mm} \mathrm{month}^{-1}$ $\left(=140 \mathrm{~mm} \mathrm{yr}^{-1}\right)$.

Direct observations are not available to compare this value with. The water budget for the BALTEX region simulated with the regional model of the German Weather Service (Europa Modell) provides data to compare with (Heise, 1996). Simulated $E-P$ is, however, almost twice of the value of this study: $260 \mathrm{~mm} \mathrm{yr}^{-1}$ for 1993, $309 \mathrm{~mm} \mathrm{yr}^{-1}$ for 1994.

There exists a number of estimates about precipitation and evaporation over the Baltic Sea [see tables in Heise (1996), Omstedt et al. (1997) and Omstedt and Rutgersson (2000)]. Omsted et al. (1997) used the $1^{\circ} \times 1^{\circ}$ grided precipitation data of the Swedish Weather Service, and evaporation was calculated using an ocean model with a bulk formula parameterization for the fluxes at the ocean surface. The annual means of $E-P$ for the years 1981-1994 are always negative. Precipitation is in excess of 38 until $309 \mathrm{~mm} \mathrm{yr}^{-1}$, with a 14 -yr mean of $150 \mathrm{~mm} \mathrm{yr}^{-1}$. The 70 -yr mean of the HELCOM (1986) study is only $100 \mathrm{~mm} \mathrm{yr}^{-1}$. Omstedt and Rutgersson (2000) recalculated the precipitation excess and came out with the same mean value. They compared that mean with other long-term means, the climate model of the Max-Planck-Institute Hamburg (ECHAM4) gives almost two times larger 

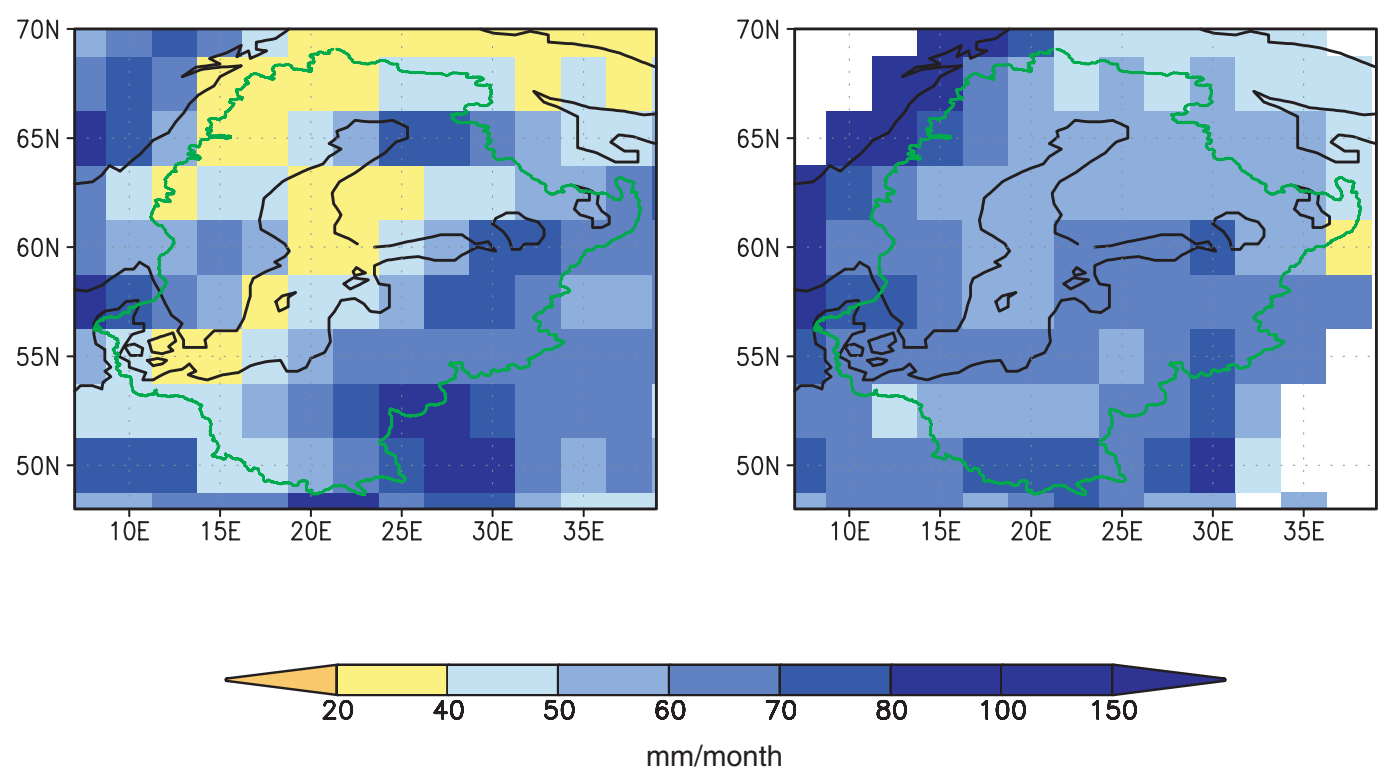

Fig. 10. Mean precipitation of the NCEP/NCAR reanalysis (left) and analysis of direct observations by F. Rubel (Rubel and Hantel, 2001) (right) in mm month ${ }^{-1}$, both averaged over the period 1996-1999.

values; the 2-yr mean derived by Heise (1996) is 104 $\mathrm{mm} \mathrm{yr}^{-1}$. Assuming that $P-E$ is larger over the land surface than over water within the BALTEX area, as most models show, then we must conclude that the value derived from the NCEP/NCAR reanalysis is an underestimation.

Rubel and Hantel (2001) have analysed the direct observations of precipitation of the BALTEX area; their results are used to check the results of the NCEP/NCAR reanalysis. A comparison of the two data sets could be carried out for the four years 1996-1999 (precipitation analysis data provided by F. Rubel). Figure 10 shows that large differences exist. The NCEP/NCAR reanalysis gives too little precipitation over the Baltic Sea and the northwest of the region. In contrary, the amount of precipitation is too large in the north of Finland and south of the Lake Ladoga, these are the two areas which show minima of $E-$ $P$ (Fig. 9). The mean precipitation over the BALTEX area, averaged for the $4 \mathrm{yr}$, is $672 \mathrm{~mm} \mathrm{yr}^{-1}$ in the NCEP/NCAR data and $733 \mathrm{~mm} \mathrm{yr}^{-1}$ in the observational data. The latter data will be used for a corrected water budget of the BALTEX area. Since there exist no direct observations or an analysis of observations of evaporation over the whole BALTEX area we cannot perform an error estimaton of $E$.

\section{Atmospheric water budget}

In order to close the budget, the difference between evaporation and precipitation must be compensated by the divergence of the vertically integrated water vapour flux and the storage term which, however, should be small averaged over a 53-yr period. A comparison of Figs. 5 and 9 shows that the budget is not closed locally. Especially large errors are obtained over the Scandinavian Mountains, in the north of Finland and south of the Lake Ladoga.

Recognizing these imbalances the question arises whether the errors cancel after integration over the whole area. Budgets averaged over the period 19482000 and over the BALTEX area are given in Table 1 for all four seasons and as annual mean. For the whole year evaporation is the dominant source of water vapour over the BALTEX area. It is about three times larger than the other source, convergence of water vapour transport. The sum of the two sources exceeds the water vapour loss by precipitation. Since the storage term is negligible, as expected, the budget is not closed. As a first rough estimation, we assume that the imbalance is equally partitioned into the three terms, so that we obtain an error of $26 \mathrm{~mm} \mathrm{yr}^{-1}$ of each term (a very conservative estimation). The error 
Table 1. Atmospheric water budget of the BALTEX area (data: NCEP/NCAR reanalysis 1948-2000)

\begin{tabular}{lrrrrrr}
\hline & $E$ & $P$ & $E-P$ & $\boldsymbol{\nabla} \cdot \mathbf{Q}$ & $\mathrm{dW}_{\mathrm{d} t}$ & Balance \\
\hline DJF $\left(\mathrm{mm} \mathrm{month}^{-1}\right)$ & 18 & 43 & -25 & -30 & -1 & 6 \\
MAM $\left(\mathrm{mm} \mathrm{month}^{-1}\right)$ & 55 & 51 & 4 & -15 & 3 & 16 \\
JJA $\left(\mathrm{mm} \mathrm{month}^{-1}\right)$ & 89 & 94 & -5 & 1 & 3 & -9 \\
SON $\left(\mathrm{mm} \mathrm{month}^{-1}\right)$ & 35 & 55 & -20 & -29 & -4 & 13 \\
Year $\left(\mathrm{mm} \mathrm{yr}^{-1}\right)$ & 591 & 730 & -140 & -218 & 0 & 78 \\
\hline
\end{tabular}

Table 2. Mean atmospheric water budget of the BALTEX area averaged over the period 1996-1999 derived from the NCEP/NCAR reanalysis data (upper row), and calculated with corrected water vapour flux divergence derived from the NCEP/NCAR reanalysis data and with precipitation analysis data from Rubel and Hantel (2001) (lower row)

\begin{tabular}{lccccc}
\hline & $E$ & $P$ & $E-P$ & $\nabla \cdot \mathbf{Q}$ & Balance \\
\hline NCEP/NCAR-Reanalysis $\left(\mathrm{mm} \mathrm{yr}^{-1}\right)$ & 559 & 672 & -113 & -245 & 132 \\
NCEP/NCAR-Reanalysis corrected $\left(\mathrm{mm} \mathrm{yr}^{-1}\right)$ & 559 & 733 & -174 & -228 & 53 \\
\hline
\end{tabular}

estimation for the divergence of the vertically integrated water vapour flux gave $16 \mathrm{~mm} \mathrm{yr}^{-1}$ due to the imbalance of the mass flux. Thus, the mass balance correction technique takes care of of about $65 \%$ of the inaccuracy of the divergence of the water vapour flux. Considering the long-term annual mean water vapour budget the three single terms can be determined from the NCEP/NCAR reanalysis data with an accuracy of about $10 \%$ or better for a region like the BALTEX area.

An attempt has been made to calculate a new budget with the most reliable data, these are the NCEP/NCAR reanalysis data for the water vapur fluxes with the mass balance correction of the divergence of the fluxes and the precipitation analysis data by Rubel (Rubel and Hantel, 2001). For the evaporation the NCEP/NCAR reanalysis data are used without any correction because we had no basis for it. Since precipitation data analysed by Rubel are available only for the four years 1996-1999, we recalculated the mean budget for this period (Table 2). The imbalance of the uncorrected reanalysis data of the four years is even larger (132.0 $\mathrm{mm} \mathrm{yr}^{-1}$ ) than the one given in Table 1 for the $53 \mathrm{yr}$. Rubel's analysed precipitation is about $10 \%$ higher than the NCEP/NCAR value. Thus, the difference between precipitation and evaporation has increased by more than $50 \%$. The convergence of the water vapour flux has been corrected due to the imbalance of the mass flux (for the $4 \mathrm{yr}$ ) by $-17 \mathrm{~mm} \mathrm{yr}^{-1}$. As con- sequence, the large imbalance of $132 \mathrm{~mm} \mathrm{yr}^{-1}$ could be reduced to $55 \mathrm{~mm} \mathrm{yr}^{-1}$ (assuming that the annual mean of storage term is negligible small). Because of the short time period the climatological representativeness and significance of these results may not be very large. The aim of this calculation, however, is to compare the results with those of the uncorrected 4-yr budget derived from the NCEP/NCAR reanalysis data and show how much a correction can amount.

The budget varies from season to season (Table 1). For the whole year precipitation exceeds evaporation by $24 \%$. Except for the spring months when these two terms balance, precipitation is always greater than evaporation but the ratio of $P / E$ varies drastically: 2.4 in winter, 1.6 in fall and 1.1 in summer. The summer season contributes most to the individual budget components: $39 \%$ of the annual precipitation and $45 \%$ of annual evaporation are obtained during summer. The water vapour transport attains its maximum during summer, too, but the divergence is negligibly small. Despite this fact, one cannot conclude that the BALTEX area is less affected by its large-scale environment during summer compared to the other seasons. A large amount of water vapour is transported into the area from west, with about the same amount leaving the area through the eastern boundary. Whether this is only a through-flow or whether precipitation and evaporation are influenced by this flow cannot be concluded based on these data. For the individual seasons 
we also calculated the water vapour storage; the decrease in winter and autumn is small compared to the other components, during spring and summer the increase is, however, of comparable size to $E-P$ and $\boldsymbol{\nabla} \cdot \mathbf{Q}$ because the latter two are small.

\section{Conclusions}

The NCEP/NCAR reanalysis data are an important source of information which can be used to study regional atmospheric hydrological cycles like that of the BALTEX area. The spatial and temporal density of these data is higher than that of any other dataset which so far has been used to investigate the hydrological cycle of this area. Despite this positive effect our results show that the errors of the calculated budget are remarkable and the budget cannot be closed. The cause of the imbalance is mainly a twofold one. First, compared to the precipitation analysis of Rubel and Hantel (2001), NCEP/NCAR reanalysis produces too little rain over the BALTEX area. That is opposite to the results of Mo and Higgins (1996), who found that the summer precipitation simulated by the NCEP model is too much over the central and eastern United States of America. Second, the largest errors have been obtained over the mountain regions, these errors are the result of the coarse vertical resolution of the reanalysis dataset. The uncorrected and corrected budget components confirm that precipitation exceeds evaporation in most parts of the BALTEX area, only over the Baltic Sea, particularly over the southern part, evaporation is larger than precipitation. The compensation of these differences is given by a convergence of the water vapour flux. Moisture is transported into the area from the west and leaves it through the eastern boundary. The BALTEX area is connected through this transport to the large-scale environment. This fact is also confirmed by the high correlation between the North Atlantic Oscillation (NAO) and the inflow and net flow. Particularly during high NAO winters, more water vapour is transported into this area than during low NAO winters, when the transport is directed more to Middle and South Europe. The mean annual and seasonal budgets provide a basis for further studies during BRIDGE (BALTEX, 1997). If the goal of BRIDGE is achieved, to obtain better and more comprehensive observations from the entire Baltic Sea catchment area, then these additional data can complete the reanalysis data to derive an atmospheric water budget which is more correct than is possible today.

\section{REFERENCES}

Alestalo, M. 1981. The energy budget of the earthatmosphere system in Europe. Tellus 33, 360-371.

Alestalo, M. 1983. The atmospheric water vapour budget over Europe. In: Variations in the global water budget. (eds. A. Street-Perrott, M. Beran and R. Ratcliffe), D. Reidel Dordrecht, 67-69.

BALTEX. 1995. Baltic Sea Experiment BALTEX. Initial Implementation Plan. International BALTEX Secretariat Publ. No. 2, 84 pp.

BALTEX. 1997. The Main BALTEX Experiment 1999 2001, BRIDGE. Strategic Plan. International BALTEX Secretariat Publ. No. 9, 78 pp.

Brogmus, W., 1952. Eine Revision des Wasserhaushaltes der Ostsee (A revision of the water budget of the Baltic Sea). Kieler Meeresforschungen 9, 15-42.

Cadet, D. and Nnoli, N., 1987. Water vapour transport over Africa and the Atlantic Ocean during summer 1979. Quart. J. R. Meteorol. Soc. 113, 581-602.

Heise, E. 1996. An investigation of water and energy budgets for the BALTEX region based on short-range numerical weather predictions. Tellus 48A, 693-707.

HELCOM. 1986. Water balance of the Baltic Sea. Baltic Sea Environmental Proceedings, 16, Helsinki, Finland, 179 pp.

Hurrell, J. 1995. Decadel trends in the North Atlantic Oscillation: regional temperatures and precipitation. Science 269, 676-679.
Kalnay, E. et al. 1996. The NCEP/NCAR 40-Year Reanalysis Project. Bull. Am. Meteor. Soc. 77, 437-471.

Karstens, U., Nolte-Holube, R. and Rockel, B. 1996. Calculation of the water budget over the Baltic Sea catchment area using the regional forecast model REMO for June 1993. Tellus 48A, 684-692.

Kistler, R. et al, 2001. The NCEP/NCAR 50-year reanalyis: monthly means CD-ROM and documentation. Bull. Am. Meteor. Soc. 82, 247-267.

Lindau, R., 2002. Energy and water balance of the Baltic Sea derived by merchant ship observations. Boreal Environ. Res. 7, 417-424.

Mo, K. C. and Higgins, R. W. 1996. Large-scale atmospheric moisture transport as evaluated in the NCEP/NCAR and the NASA/DAO reanalysis. J. Climate $\mathbf{9}, 1531-1545$.

Omstedt, A., Meuller, L. and Nyberg, L. 1997. Interannual, seasonal and regional Variations of Precipitation and Evaporation over the Baltic Sea. Ambio 26, 484-492.

Omstedt, A. and Rutgersson, A. 2000. Closing the water and heat cycles of the Baltic Sea. Meteorol. Z. 9, 59-66.

Omstedt, A., Gustafsson, B., Rodhe, J. and Walin, G. 2000. Use of Baltic Sea modelling to investigate the water cycle and the heat balance in GCM and regional climate models. Climate. Res. 15, 95-108.

Palmen, E. 1963. Computation of the Evaporation over the Baltic Sea from the Flux of Water Vapor in the 
Atmosphere. Publ. Int. Assoc. of Scientific Hydrology, 62, 244-252.

Raschke, E. et al. 2001. The Baltic Sea Experiment (BALTEX): A European Contribution of the Investigation of the Energy and Water Cycle over a Large Drainage Basin. Bull. Amer. Meteor. Soc. 82, 2383-2413.

Rasmusson, E. M. 1967. Atmospheric water vapor tranport and the water balance of North America. Part I: Characteristics of the water vapor flux field. Mon. Wea. Rev $\mathbf{9 5}$, 403-426.

Rasmusson E. M. and Mo, K. C. 1996. Large-Scale Atmospheric Moisture Cycling as Evaluated from NMC Global Analysis and Forecast Products. J. Climate 9, 3276-3297.

Rubel, F. and Hantel, M. 2001. BALTEX 1/6-degree daily precipitation climatology 1996-1998. Meteor. Atmos. Phys. 77, 155-166.

Ruprecht, E., Schröder, S. S. and Ubl, S. 2002. On the relation between NAO and water vapour transport towards Europe. Meteor. Zeitschr. 11, 395-401.

Simojoki, H., 1948. On the Evaporation from the Northern Baltic. Geophysica 3, 123-126.

Smirnov, V. V. and Moore, G. W. K. 1999. Spatial and Temporal Structure of Atmospheric Water Vapor Transport in the Mackenzie River Basin. J. Climate, 12, 681-696.

Speth, P. and Skade, H. 1977. An investigation of the atmospheric heat and moisture balance in the Baltic Sea region. Part I: Aerological climatology. Meteor. Rundschau 30, $72-91$.

Trenberth, K. and Guillemot, C. 1998. Evaluation of the atmospheric moisture and hydrological cycle in the NCEP/NCAR reanalysis. Clim. Dyn. 14, 213-231.

WMO, 1990. Scientific Plan for the Global Energy and Water Cycle Experiment., WMO-Technical Document, TD-376, $83 \mathrm{pp}$. 